\title{
GPS and EDM monitoring of Unzen volcano ground deformation
}

\author{
Takeshi Matsushima ${ }^{1}$ and Akimichi Takagi ${ }^{2}$ \\ ${ }^{1}$ Institute of Seismology and Volcanology, Faculty of Sciences, Kyushu University, Shimabara 855-0843, Japan \\ ${ }^{2}$ Seismolgical and Volcanological Department, Japan Meteorological Agency, Tokyo 100-8122, Japan
}

(Received January 13, 2000; Revised June 14, 2000; Accepted July 14, 2000)

\begin{abstract}
Following 198 years of dormancy, an eruption started at Mt. Fugen, the main peak of Unzen volcano, in Kyushu, Japan, in November 1990. A dacite lava dome began to grow in May 1991. We installed the surveying points of GPS in 1992 around the lava dome in order to observe the ground deformation that accompanied the growth of the lava dome. In the winters of 1993 and 1994, we observed swift ground deformations that radiated from the vent of the volcano. It was presumed that rising magma accumulated and expanded the volcano body. After the lava effusion stopped in 1995, we also installed surveying points on the lava dome. EDM mirrors were permanently fixed to the large rocks with bolts. A GPS survey was carried out 2 or 3 times each year to estimate the 3-dimensional displacement. The result of the EDM survey showed that the baselines from the flank of the volcano were shortening $5 \mathrm{~mm}$ per day, and the result of the GPS survey showed that the displacement vector of the dome was parallel to the direction of the steepest slope of the old volcano body. This indicates that the inside of the lava dome is still very hot, and that deformation of the dome is viscous.
\end{abstract}

\section{Introduction}

Unzen volcano is one of the active volcanoes in Kyushu in Japan (Fig. 1). After spilling out lava from the northeastern flank of the volcano in 1792, earthquake swarms occurred under the volcano. Two especially heavy earthquakes on May 21 collapsed Mt. Mayuyama on the eastern part of Unzen volcano. A large-scale debris avalanche rushed into the Ariake Sea, generating a large tsunami. The tsunami attacked the area on the opposite shore, and at least 15000 people died.

In 1989, 197 years after the last eruption, earthquake swarms started under Chijiwa Bay, situated on the western side of Unzen volcano. The epicenters moved eastward, became shallow, and approached the summit area of Unzen volcano. The eruption started at Mt. Fugen, which is the main peak of Unzen volcano, on November 17, 1990. We were anxious about the mountain collapsing as it did in 1792 . Global positioning system (GPS) equipment was introduced to monitor the collapse of Mt. Mayuyama. However, there were few big earthquakes, and there was no collapse of the mountain this time.

Lava appeared from the crater on the east side of the summit of Mt. Fugen on May 20, 1991. The lava of this eruption had large viscosity, so it formed a dome on and around the crater rather than moving down the flank as a lava flow. The lava dome grew day by day and collapsed often on a large scale. Destructive pyroclastic flows occurred from the collapse, resulting in large damage to the east flank of the volcano. Forty-three persons, including scientists and news reporters, died in the flames resulting from pyroclastic flows on June 3, 1991.

Copy right $(\mathrm{C})$ The Society of Geomagnetism and Earth, Planetary and Space Sciences (SGEPSS); The Seismological Society of Japan; The Volcanological Society of Japan; The Geodetic Society of Japan; The Japanese Society for Planetary Sciences.
The volume rate of the lava that extruded was about $3 \times$ $10^{5} \mathrm{~m}^{3}$ or more per day for the first year. The rate of the extrusion changed with time; when it was rapid, Mt. Fugen expanded, followed by shrinking after appearance of a new lava lobe. GPSs, Electronic distance measurements (EDMs), and the tiltmeters that were installed on the outskirts of a dome recorded these deformations of Mt. Fugen. The lava dome continued to grow until the spring of 1995 , finally reaching a volume of $1 \times 10^{7} \mathrm{~m}^{3}$. The lava dome was named Heisei Shinzan. When the danger of a large collapse of the dome had passed, we were able to install GPS observation points and EDM target mirrors on the dome.

In this paper, we present result of GPS and EDM observations around and on the lava dome, and discuss origin of these volcanic ground deformations.

\section{Observation of the Volcano Deformation Caused by Magma Intrusion}

\subsection{Result of continuous GPS observation}

Mt. Fugen extrudes high-viscosity lava from a crater, and a lava dome began forming over the crater in May 1991. At this time, the data from surrounding tiltmeters and the EDM survey shows that the big crustal movement occurred on the outskirts of the crater (e.g., Saito et al., 1993; Yamashina and Shimizu, 1999). Regrettably, since the GPS had not yet been arranged, the 3-dimensional crustal movements were not recorded accurately.

In June 1992, two sets of receivers were installed on the western crater field (FGI, RBB), from which one can approach the dome easily and safely (Fig. 2). Continuous observation was started between these surveying points and a fixing point on the caldera rim of the volcano (NIT) (Ohmi and Matsushima, 1993). Antennas were fixed to solid rocks with bolts, and 8 hours of observation was carried out every 


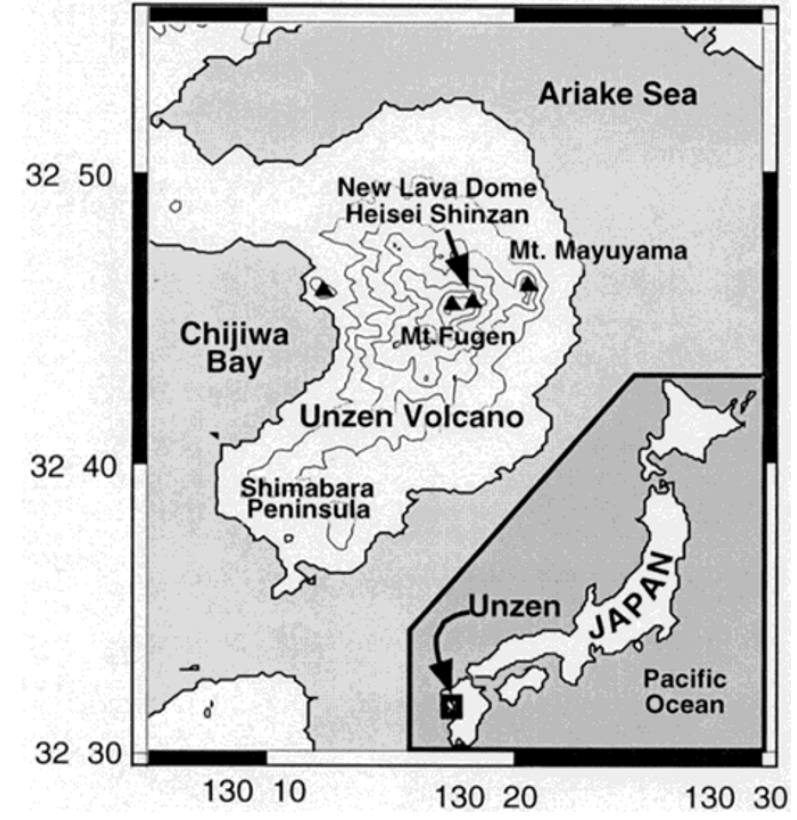

Fig. 1. Location map of Unzen Volcano in Kyushu Island, Japan. Three historical eruptions including the 1990-1995 eruption are recorded only at Mt. Fugen, the main peak of the volcano.

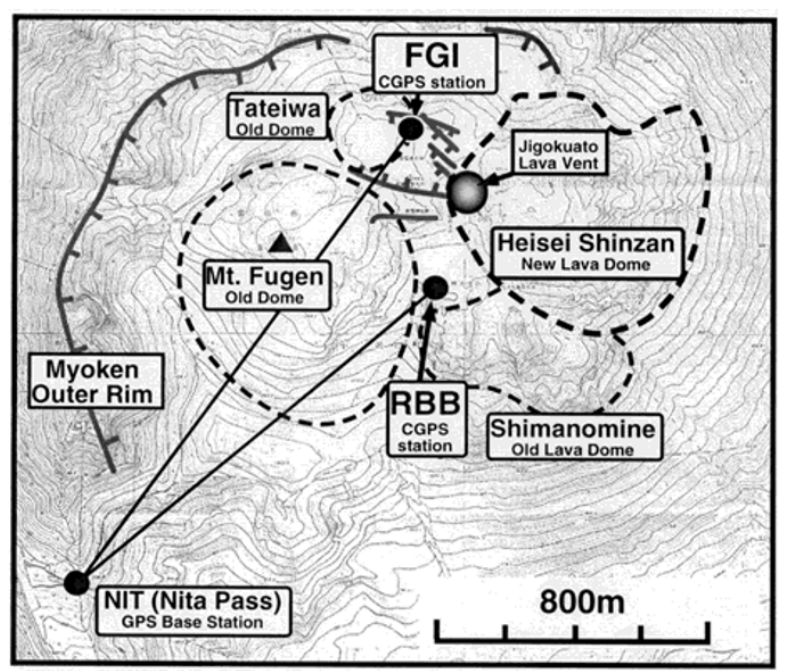

Fig. 2. Location map of continuous GPS observation sites on Mt. Fugen. Two GPS receivers were equipped on the west side of the new lava dome called Heisei Shinzan. The shape of the dome was as of Jan. 1993. It is estimated that the other old lava domes were formed 4000 years or more ago.

day. The power supply used lead storage batteries and solarcell panels. Observation was occasionally interrupted when poor weather persisted or when volcanic ashes adhered to the solar-cell panels, causing the storage batteries to discharge. We climbed the volcano once every 2 weeks, connected a laptop computer to the receiver, and retrieved GPS data recorded in the internal memory. We used the Static method for data analysis. The baseline length between a fixing point and surveying points is less than $2 \mathrm{~km}$, and the difference of height is also less than $300 \mathrm{~m}$. The measuring accuracy was very good, and we were able to determine relative positions within about $5 \mathrm{~mm}$ horizontally and within about $1 \mathrm{~cm}$ vertically.

Horizontal changes in the position of FGI in relation to NIT from June 1992 to the end of September 1993 are shown in Fig. 3. The FGI point is about $250 \mathrm{~m}$ west-northwest of the dome. There were no large changes through January 1993, but beginning in February 1993, rapid west-northwest displacement was observed. The daily displacement speed equaled about $1.5 \mathrm{~cm}$ per day and eventually totaled about 40 $\mathrm{cm}$. After that, the displacement velocity was reversed, and the change between the two positions returned by about $5 \mathrm{~cm}$, eventually stopping in mid-April. These phenomena agree with the fact that the amount of lava extrusion revitalized again to about $3 \times 10^{5} \mathrm{~m}^{3}$ per day after the amount fell temporarily to 5 to $6 \times 10^{4} \mathrm{~m}^{3}$ per day in January 1993 (Nakada et al., 1999).

Although the 10th lobe that began extrusion from the dome summit early in February experienced continued active growth initially, the extrusion mouth was closed under the weight of itself in March. Therefore, the lava from underground began to accumulate in the inside under the dome and press the ground around the dome. The rapid west-northwest displacement observed at FGI occurred in response to this influence. The east slope of the dome crashed in mid-April, and lava extruded quickly as the 11th lobe. Therefore, the pressure to the western side of the dome stopped, and the displacement at FGI was reversed.

\subsection{Result of repetitive GPS observation}

In October 1993, we switched from continuous GPS observation using the Static method to repetitive GPS observation using the Rapid Static method for the following three reasons: (1) the number of GPS satellites that can be observed increased, with survey results of the Rapid Static method having almost the same accuracy as those of the Static method, with a measurement time of about 10 minutes; (2) since the direction of dome-growth changed to the western side, the possibility of loss of equipment was raised; and (3) since the measurement time is short with Rapid Static GPS observation, it is possible to survey many points.

Figure 4 shows the amount of horizontal displacements and the amount of vertical displacements, which were calculated by the Rapid Static method from January 24 to February 27, 1994. Growth of the endogenous dome on the western side had begun quickly in the middle of January in Mt. Fugen. Because the 11th lobe on the east slope has grown large covering the vent like a lid, the lava that lost an exit pushed out on the western side. The old volcano body of the western side of the dome received big pressure as a result of this effect, and the ground radiated several meters in one month from the dome center. A landslide also occurred on the north-side slope and several $10-\mathrm{cm}$ displacements were observed in one day. Some researchers thought that this expansion originated with the intrusion of magma in a new direction, and also that there was a danger of a large-scale collapse of the volcano. However, as a result of our GPS survey, the center of expansion was presumed to be near the Jigokuato crater that is the conventional vent, and the possibility of a large-scale collapse was deemed unlikely.

\section{Observation of the Lava Dome Deformation}

The extrusion of lava almost halted and growth of the lava 


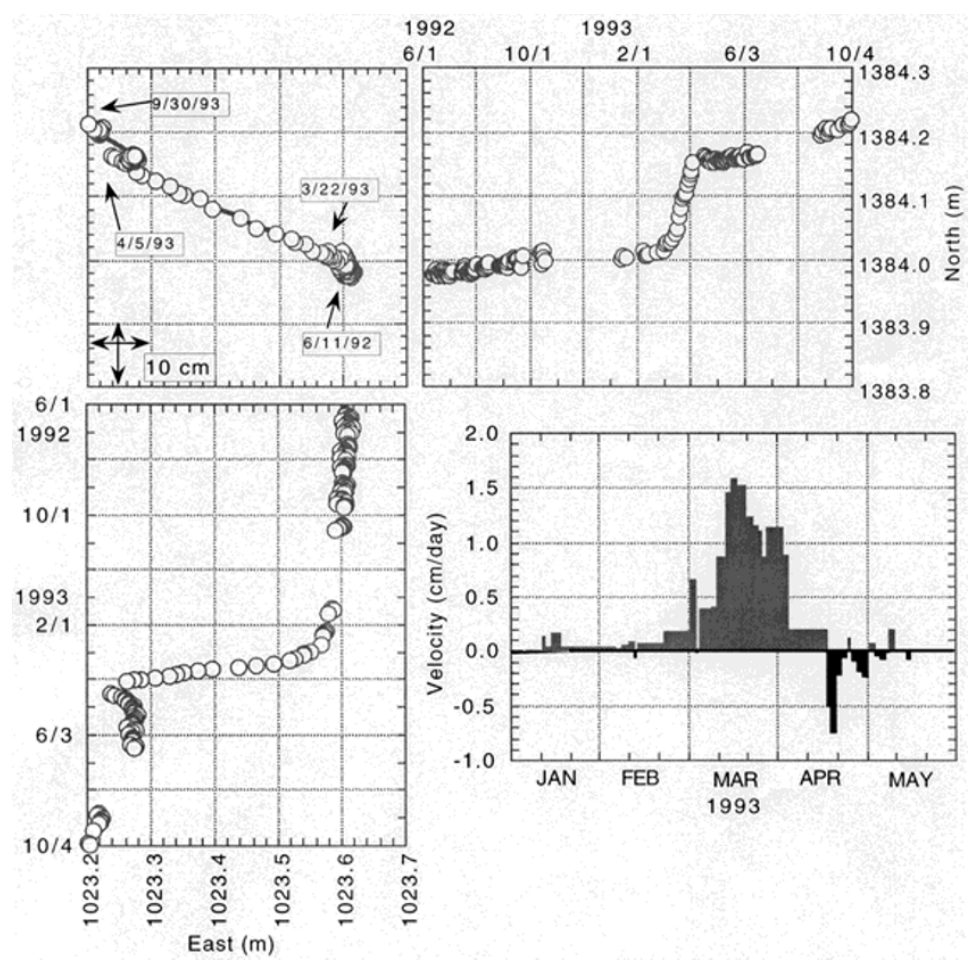

Fig. 3. Horizontal displacement at FGI continuous GPS station. The rapid expansion by the rise of a lot of magma was observed from the end of February to the beginning of April 1993. In mid-April the movement was reversed, and stopped early in May.

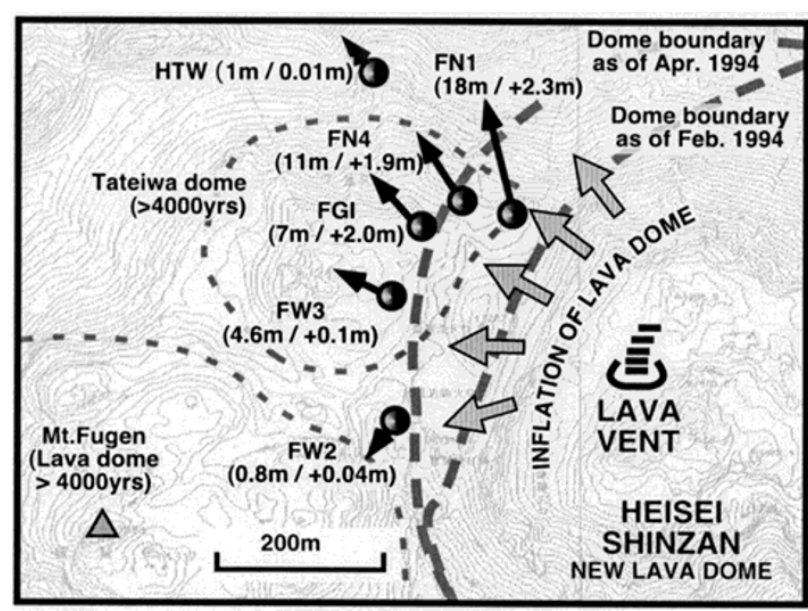

Fig. 4. Displacement observed from Jan 24, 1994 to Feb. 27 (35 days). Values are horizontal/vertical displacements in unit of meter. Wide arrows represent the directions of inflation of the Lava dome.

dome also stopped in January 1995. In about four years, the lava dome had grown to a size of about $1000 \mathrm{~m}$ east and west and about $500 \mathrm{~m}$ north and south, with a height of about $230 \mathrm{~m}$ and a volume of about $1 \times 10^{8} \mathrm{~m}^{3}$. The pyroclastic flows generated by the collapse of the lava dome ceased after spring 1995, at which time dome observation was attained. The dome is in the shape of a plateau and the crushed lava covers the dome. The lumps of lava range from $10 \mathrm{~cm}$ to several meters in diameter and are stacked up like a mountain of tiles and pebbles.

We installed GPS observation points and EDM target mirrors on the dome and started observation in May 1995. Usu- ally, we had seven GPS observation points and four target mirrors in operation; however, there were times when measurement became impossible because of rock falls or corrosion caused by volcanic gas. The GPS observation point was the 5/8-inch bolt made from stainless steel embedded on a stable rock on the dome, and the GPS antenna was directly fixed on the bolt when observation was made. EDM target mirrors were permanently fixed to the upper part of other stainless bolts embedded on the dome.

The 11th lava lobe is in the steep slope of the east side of the lava dome, and it could not be reached on foot. In 1996 the Ministry of Construction installed concrete lumps using a helicopter, and target mirrors were affixed to these concrete lumps in eight places of the lobe. An EDM survey was carried out from several places on the flank of the volcano. We measured the distance several times in one year between evening and early morning, when the temperature gradient of the atmosphere is nearly stabilized. A GPS survey was carried out 2 or 3 times in one year. The observation time at each point was about 10 minutes, and we used the Rapid Static method for analysis of the data.

Figure 5 shows the result of EDM observations for four years after beginning in 1995. Each baseline between the target mirror on the dome and the observing point on the flank of the volcano has shrunk. The change of the east edge of the dome was the largest, and the distance was shortened by no less than $3 \mathrm{~m}$ in four years. Although the speed of shortening is slowing gradually, the curve of the graph is changing smoothly. This fact shows that the lava dome is not deformed by earthquake damage but rather changing shape slowly with viscosity.

Figure 6 shows the amount of deformation of the lava dome 


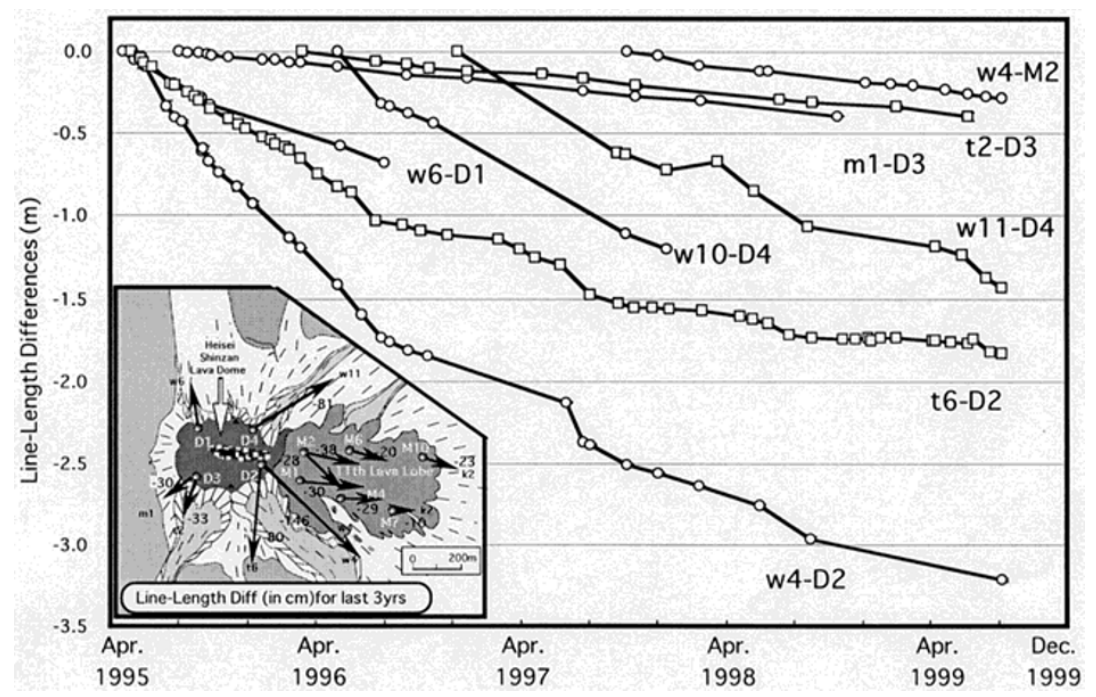

Fig. 5. Line-length differences of EDM points on the dome observed from the flank of the volcano.

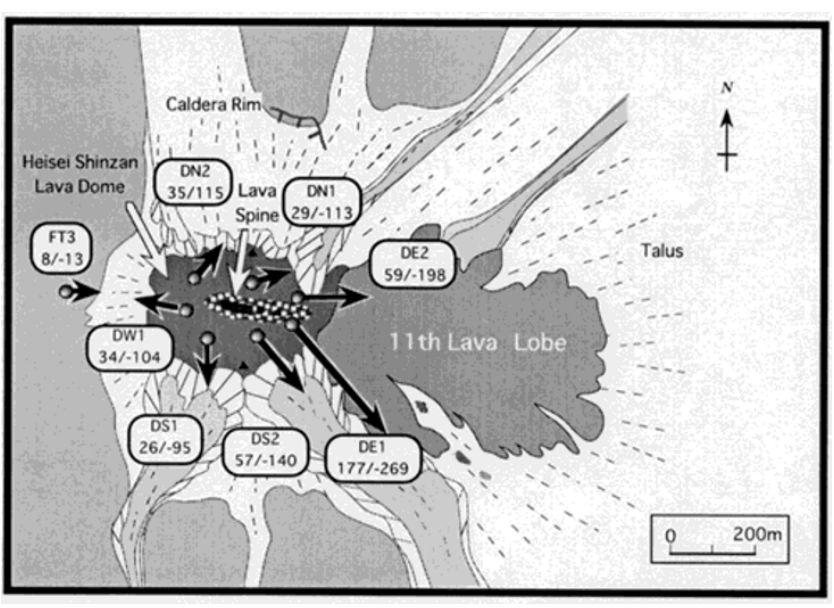

Fig. 6. Displacement of the dome observed by GPS survey from August 1996 to August 1999. Values are horizontal/vertical displacements in unit of $\mathrm{cm}$.

for three years measured by the GPS, with which we can calculate the amount of 3-dimensional deformation of a lava dome. The GPS survey showed that the displacement vector of the dome was parallel to the direction of the steepest slope of the old volcano body, which indicates that the temperature inside the lava dome is still very high and that deformation of the dome is viscous. Therefore, the dome is deformed like a spoonful of jelly on a tilted plate, and its displacement is largest where the slope is the steepest. However, the 11th lobe that is spreading on the east side has a small displacement. Since the lobe is thin, we believe it has cooled and solidified. Moreover, the displacement at the old volcano body (point FT3) shows the direction of the vent of the dome. This shows that cooling contraction of the lava dome has taken place simultaneously.

The temperature of the volcanic gas currently emitted from the central part of the dome was a maximum of $800^{\circ} \mathrm{C}$ in 1995 , and it is about $400^{\circ} \mathrm{C}$ now (SEVO, 1999). The dome is cool enough that snow can lie on it in winter in all except the central part. The decline of the temperature of this volcanic gas justifies our lava-dome deformation model.

\section{Conclusion}

We were able to measure the crustal movement caused by the volcanic activity in Unzen volcano precisely using GPS and EDM surveying systems. We have observed expansion of the volcano body accompanied by a rise of the lump of magma, and subsequent contraction. We have also observed viscosity-deformation of a lava dome and the deformation accompanied by cooling contraction.

These results of GPS and EDM surveys are very useful for the purpose of both volcanic research and disaster prevention.

Acknowledgments. The authors express their gratitude to staff at the Unzendake Weather Station of JMA, the Shimabara Volcano and Earthquake Observatory of Kyushu Univ., and the Japanese Ground Self-Defense Force who assisted in risky observations of an active volcano. The comments and careful reviews from Prof. P. Segall and Prof. M. Tanaka improved the manuscript greatly. EDM target mirrors on the 11th lava lobe were installed by the Ministry of Construction, Japan.

\section{References}

Nakada, S., H. Shimizu, and K. Ohta, Overview of the 1990-1995 eruption at Unzen volcano, J. Volcanol. Geotherm. Res., 89, 1-22, 1999.

Ohmi, S. and T. Matsushima, Ground deformation around the lava dome of Unzen Volcano Monitored with GPS, Bull. Volcanol. Soc. Japan, 38, 129-133, 1993 (in Japanese).

Saito, E., S. Suto, T. Soya, K. Kazahaya, Y. Kawanabe, H. Hoshizumi, K. Watanabe, and H. Endo, Geodetic monitoring using EDM before and during the 1991-1992 lava extrusion of Fugen-dake, Unzen Volcano, Kyushu, Japan, Bull. Geol. Surv. Japan, 44, 639-647, 1993 (in Japanese with English abstract).

Shimabara Earthquake and Volcano Observatory (SEVO), Volcanic Activity of Unzen Volcano (February 1999-May 1999), Report of Coordinating Committee for Prediction of Volcanic Eruption, 74, 103-108, 1999 (in Japanese).

Yamashina, K. and H. Shimizu, Crustal deformation in the mid-May 1991 crisis preceding the extrusion of a dacite lava dome at Unzen volcano, Japan, J. Volcano. Geotherm. Res., 89, 43-55, 1999.

T. Matsushima (e-mail: mat@sevo.kyushu-u.ac.jp) and A. Takagi 